\title{
Modification of early strength parameters of concrete by the addition of fly ash and admixture of nano C-S-H for application in 3D printing
}

Bartosz Szostak ${ }^{1}$, Grzegorz L. Golewski ${ }^{2}$

${ }^{1}$ MSc. Eng., Lublin University of Technology, Poland

${ }^{2}$ Prof. , Lublin University of Technology, Poland

\begin{abstract}
In the paper, the authors present the results of tests concerning traditional cement mortars with the addition of silica fly ash and the C-S$\mathrm{H}$ nano-admixture. The use of fly ash results in improved plasticity of the mixture. The use of the C-S-H nano-admixture has a positive effect on shortening the setting time and a rapid increase in the strength of mixtures without losing their subsequent properties, which is presented in the research described in the paper. On this basis, the impact of fly ash and the nano-admixture on the selected parameters of the cement paste in the early maturation periods was determined - after 4, 8, 12, 24, 72h and also 7 and 28 days. The following tests were carried out on previously prepared samples: the compressive strength test on a hydraulic press, the test of setting time and the test of cement matrix shrinkage.
\end{abstract}

\section{Introduction}

The construction industry has been increasingly developing in recent years, which is manifested, among other things, in the increasing use of the 3D printing of concrete buildings [17]. The development of this innovative technology is connected with the necessity to develop new concepts for the implementation of such structures and materials for their execution [8].

A very important feature of concretes from which houses are printed is their early compressive strength and ductility [16][18][7][25]. This problem concerns mainly composites with modified structure. It should be noted that the properties of such materials are both different at an early age, from those of traditional concretes, and change in a different way during the curing process compared to concretes made with ordinary Portland cement. These phenomena are described in detail, among others, in the papers [5-13].

At present, chemical modifications and geopolymer concretes are the most common ways to improve the early age parameters of composites with cement matrices [1]. However, a big issue related to chemical modification of concrete is its rheological behavior and negative influence on other material parameters. The use of chemical admixtures, which accelerate the process of cement grains' bonding, is often associated with the increased hydration heat release and shrinkage of the cement matrix. This results in micro- and macrocracks in the structure of the finished composite, which negatively affects a number of its parameters, such as compressive and tensile strength, fire resistance, fracture toughness, water resistance, or resistance to chemical corrosion (e.g. due to salt compounds). This significantly translates into both the safety of structures made of these materials and their increased failure rate during operation.

Very fast development can be observed in the case of the geopolymer concretes. They are characterized by high early strength and good mechanical parameters of the matured composite. At the moment, however, such a solution is very expensive, thus it is necessary to look for economically justified alternatives. Moreover, while taking actions aimed at improving the early age parameters of the composites, it is also necessary to pay attention to the ecological

Corresponding author: g.golewski@pollub.pl 
benefits which could result from such solutions. Since the worldwide cement production contributes to the release into the atmosphere of compounds negatively influencing the environment [25], the use of cement substitutes (SCMs), e.g. [3][4][22][25-28], is also beneficial from the ecological point of view. One of such materials which can successfully replace the cement is the siliceous fly ashes (FA). They are waste generated during coal combustion in power plants. Their storage has a degrading effect on the environment, therefore their utilization, through their application in the composites, is very environment-friendly [29].

In order to meet the above trends, the following paper presents the results of research on the traditional cement pastes with the addition of silica fly ashes and the C-S-H nanoadmixture. The purposefulness of studying the properties of concretes modified with one of the most frequently used mineral additives [30] in combination with the modern chemical admixture [31] results from the following two facts [32]:

- the FA use has a positive impact on the economic aspect as it reduces the cost of concrete production by reducing the content of expensive cement in its composition,

- the ecological effects of the presented activities are reflected in the reduction of the amount of troublesome industrial waste landfills, the $\mathrm{CO}_{2}$ reduction and other greenhouse gas emissions from the cement production process,

- the FA use results in improved plasticity of the concrete mix.

The use of the C-S-H nano-admixture, on the other hand, has a positive effect on shortening the setting time and rapid increase in the concrete strength without losing its subsequent properties. This can be confirmed by the results of the research, which are presented in the following publication. On the basis of these results, it will be possible to demonstrate whether the presented solutions for the material modification of concrete can constitute a real and effective proposal of a material that can be used in the house-printing technology.

\section{Experimental research}

\subsection{Aim and scope of research}

In the course of experimental studies, mechanical and physical parameters of the reference cement pastes (without the C-S-H nano-admixture), and the FA and the C-S-H nano-admixture modified ones were compared. On this basis, the effect of FA and the nanoadmixture on selected parameters of the pastes in early stages of their maturation was determined, i.e. after: 4, 8, 12, 24, and 72h.

Additionally, the same parameters were tested after 28 days of maturation of the composites in order to determine the influence of the applied modifications on the standard parameters of the pastes in question [14].

To this end, the following tests were carried out:

- the compressive strength,

- the setting time,

- the shrinkage of the cement matrix. 


\subsection{Cement pastes used in the research and their preparation}

Four types of materials were used in the study, differentiated in terms of the content of the fly ash and the nano-admixture of the C-S-H crystals. A ready-made aqueous solution with the nanocrystals of hydrated calcium silicate - the Basf Master X-Seed 1000 was used for the tests. The water-binder ratio and the amount of additives and admixtures used results from previous experimental studies of the authors [23]. There was no need to use additional plasticizers when making samples.

The following compositions of cement pastes were tested:

- $0 \%$ FA and $4 \%$ C-S-H: FA-0 CSH-4,

- $20 \%$ FA and $4 \%$ C-S-H: FA-20 CSH-4.

- $0 \%$ FA and $0 \%$ C-S-H: FA-0 CSH-0,

- $\quad 20 \%$ FA and $0 \%$ C-S-H: FA-20 CSH-0.

Samples for the compressive strength and shrinkage measurements were made according to the standard recommendations [30-32]. The test samples were made in the tripartite moulds, each chamber has internal dimensions of $160 \times 40 \times 40 \mathrm{~mm}$. The moulds were lubricated inside with a layer of a non-reactive anti-adhesive agent which prevents the paste from sticking during binding process and facilitates the demoulding of samples. The moulds were then filled with the paste a few mm above half their height and the first compaction was performed. After the samples were thoroughly vibrated, the moulds were filled in the entire volume. The excess mixture was removed with a steel trowel. The second compaction was then performed. Both compaction cycles were performed on the SWE-08 vibrating table with a vibration frequency of $52.7 \mathrm{~Hz}$ and a vibration amplitude of $0.67 \mathrm{~mm}$. The compaction of each layer lasted about $30 \mathrm{~s}$. The samples prepared in this way were left to bind in the moulds under laboratory conditions - temperature $20^{\circ} \mathrm{C} \pm 2{ }^{\circ} \mathrm{C}$. They were protected against water loss. Next, the samples were demoulded and labeled. The samples for the compressive strength testing were demoulded after $4 \mathrm{~h}, 8 \mathrm{~h}$, and $12 \mathrm{~h}$ and the remaining ones after $16 \mathrm{~h}$ and they were placed in a water bath.

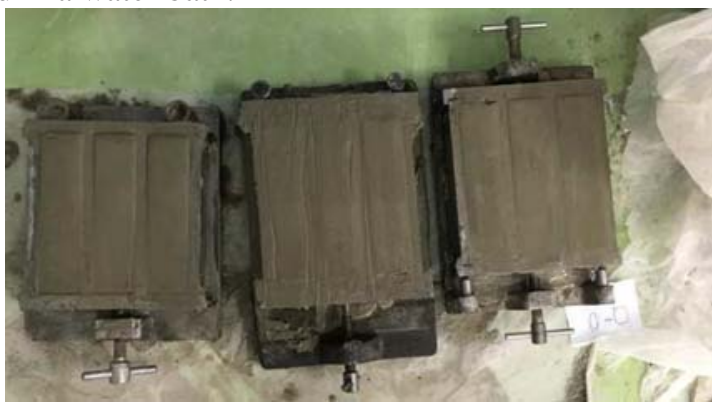

Fig. 1 Samples prepared in the tripartite moulds for the compressive strength testing.

\subsection{Experimental studies}

\subsubsection{Compressive strength}

The preparation of samples and the course of testing the compressive strength was performed according to the recommendations of the standard [30]. The tests were performed on the MTS 809 Axial/Torsional Test System strength machine. For each series, 6 samples were prepared for testing. 


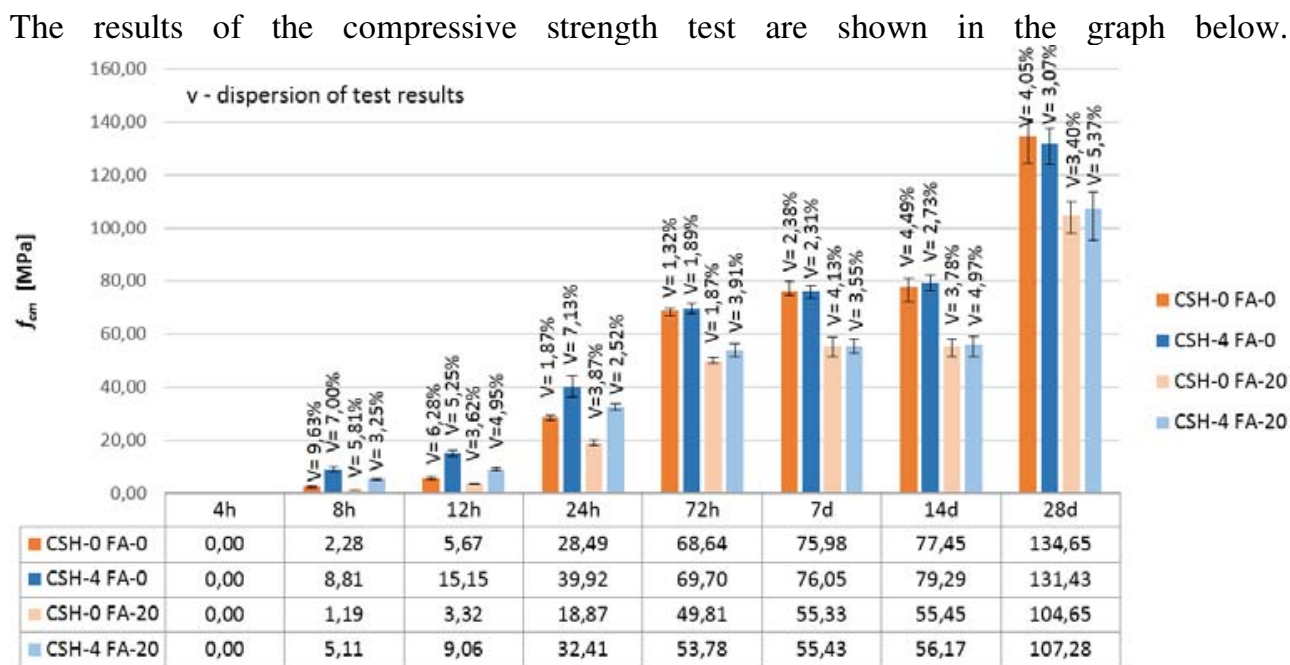

Fig. 2 Results of the compressive strength test of the composites tested.

After 4 hours, the samples could not be demoulded so as not to damage their structure. In the subsequent periods, the negative influence of the FA on the early strength parameters of cement paste was confirmed. In the first hours of maturation, a nearly double decrease in the compressive strength was observed for samples in which a cement substitute in the form of the FA was used. Over time, these differences decreased, however, until the very end they were clear (after 28 days, the compressive strength of samples with the FA was on average $20 \%$ lower than the pastes without the FA addition).

However, a significant influence of the $\mathrm{C}-\mathrm{S}-\mathrm{H}$ nano-admixture was observed. After 8 hours the strength of FA- 0 CSH- 4 and FA-20 CSH- 4 samples was almost 4 times higher than the reference samples. The applied nano-admixture also eliminated the negative influence of the FA on the early strength of the composite. This means that the application of the nanoadmixture almost completely equalizes and even increases the compressive strength in the first $24 \mathrm{~h}$ of the maturation period.

After 72 hours, the strength parameters of cement pastes with and without the nanoadmixture were already similar. The application of the nano-admixture did not affect the compressive strength after 28 days and the spread between the results in each series.

\subsubsection{Rheological deformations}

During the tests, the shrinkage was measured. It was carried out according to the standard guidelines. For each series, 3 samples were prepared for testing. The experiments were carried out in the Graf-Kaufman's apparatus. The measurements were taken every day starting from the first day after the samples were formed. After demoulding, the samples were examined for the first time and placed in a desiccator. Before the beginning of the test, the Graf-Kaufman's apparatus was leveled with screws placed in the base. Additionally, before each measurement, the instrument was manually calibrated with a standard for the base value appropriate for each sample. The stubs on the samples were cleaned each time before being placed in the instrument. 


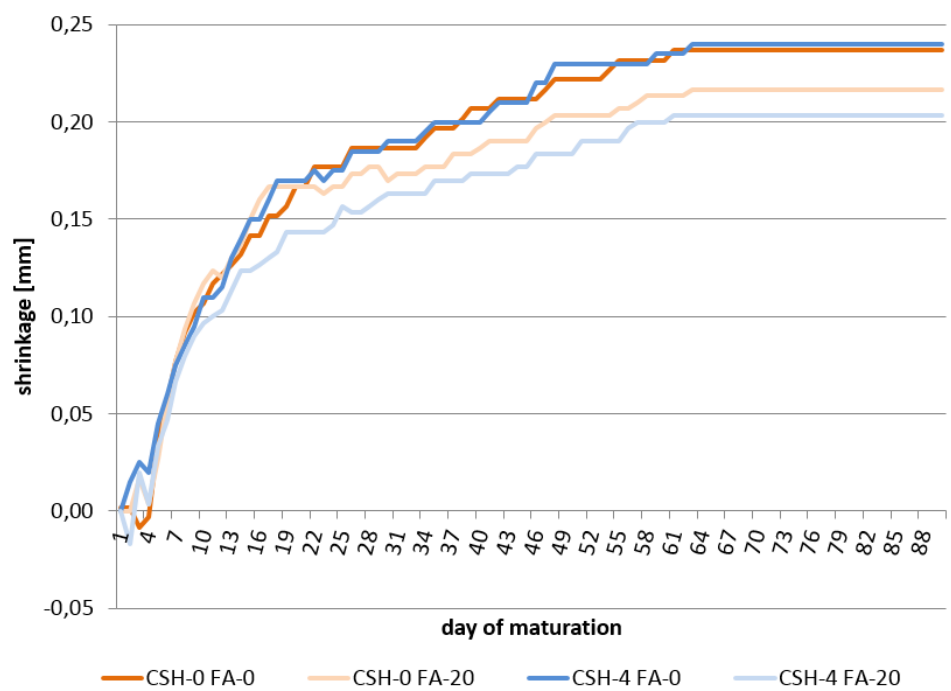

Fig. 3 Diagram showing the shrinkage results of the cement matrix of the composites tested.

On the basis of the conducted research, it was found that the average value of shrinkage for individual pastes is similar in the initial period of the composite maturation. Swelling of all the samples except FA-0 CSH-4 was also observed in the first few dozen hours of maturation. It results from the maturating conditions of the samples. After 72 hours, all the samples showed shrinkage.

After about 10 days, the differences began to increase. After 50 days, the difference reaches its maximum value of $0.05 \mathrm{~mm}$ (between FA-0 CSH-0 and FA-20 CSH-4).

There was a marked difference in the amount of shrinkage between the cement pastes without the FA (FA-0 CSH-0 and FA-0 CSH-4) and those with the FA (FA-20 CSH-0 and FA-20 CSH-4). The presence of this additive significantly reduced the size of cement matrix shrinkage. Clearly, the lowest shrinkage values on the final day of the test were observed in the paste containing the FA and the C-S-H nano-admixture (FA-20 CSH-4). The highest values were obtained by the unmodified paste (FA-0 CSH-0) and the one modified with the C-S-H (FA-0 CSH-4). According to the standard recommendations, the samples were tested 90 days after their formation.

\subsubsection{Setting time of the cement pastes}

Preparation of samples for the determination of setting time was carried out according to the standard [30]. The samples were stored in a chamber where the temperature was $20^{\circ} \mathrm{C}$ and relative humidity was above $50 \%$. The components of each mixture were mixed according to the standard guidelines in the amount needed to make 5 samples of each of the composites tested. Next, a ring covered with an anti-adhesive agent was placed on the base plate and the cement paste was transferred to it. Excess of paste was removed with a metal cutting tool in order to smooth the upper surface.

The filled rings were placed in a water container so that the samples were immersed - the surface of the sample was $5 \mathrm{~mm}$ below the surface of the water. Samples were examined every 10 minutes. Each ring was placed in the Vicat's apparatus calibrated against the base plate used. The needle was lowered until it came into contact with the paste. The locking screw was then released after 1 second. At the end of the cavity (maximum 30 seconds), the distance between the tip of the needle and the base plate was read. The needle was cleaned. Subsequent cavities were made more than $8 \mathrm{~mm}$ from the edge, $5 \mathrm{~mm}$ from each other and 
$10 \mathrm{~mm}$ from the previous measurement site. Between the tests, samples were placed in a climatic chamber. The time, referred to as the beginning of the setting time, was determined when the distance of the needle from the base plate was equal to $6 \pm 3 \mathrm{~mm}$.

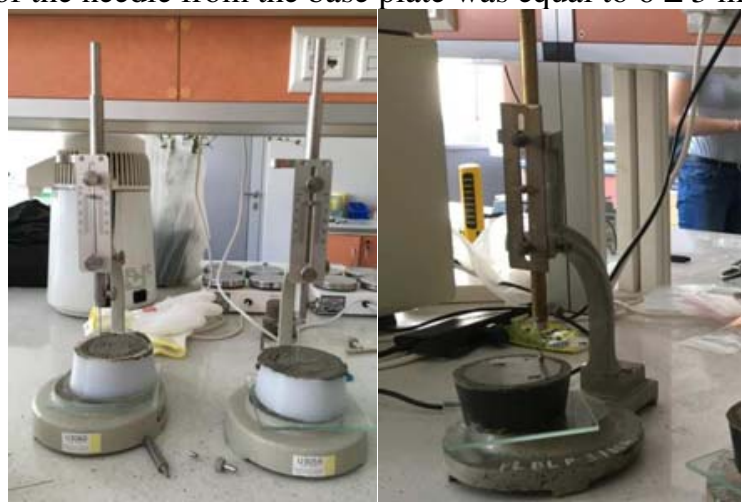

Fig. 4, Fig. 5 Testing the beginning and end of the setting time.

The end of setting time was determined at the moment when only the tip of the needle was marked on the surface of the sample, without the shape of the cap ring. In this case, the test result should be confirmed by taking a second reading in the next place.

The tests were carried out on 5 samples for each mixture. The table below shows the averaged results. None of the results deviated significantly from the rest and they were all taken into account to determine the average value.

Table 1 Table showing the time of beginning and end of setting time of the composites tested.

\begin{tabular}{|c|c|c|c|c|}
\hline $\begin{array}{c}\text { SETTING TIME } \\
{[\text { min] }}\end{array}$ & \multicolumn{2}{|c|}{ CSH-0 } & \multicolumn{2}{c|}{ CSH-4 } \\
\cline { 2 - 5 } & FA-0 & FA-20 & FA-0 & FA-20 \\
\hline Beginning & 260 & 270 & 160 & 170 \\
\hline End & 295 & 305 & 190 & 205 \\
\hline Duration & 35 & 35 & 30 & 35 \\
\hline
\end{tabular}

During the tests it was found that setting time for all mixtures is very similar (30-35 min). However, they differ significantly in terms of the beginning of setting time. Mixtures modified with the C-S-H nanocrystals showed the beginning of setting time definitely earlier in comparison to the unmodified ones. The difference was 100 minutes in relation to the reference cement pastes both for composites with and without the addition of the FA.

The nano-admixture affected only the beginning of setting time and not its duration. This means that with the application of the C-S-H nano-admixture there was enough time to build a suitable microstructure of the composite. Additionally, an extension of the setting time was observed for samples with the FA and C-S-H nano-admixture. The increase in the setting time positively influences the microstructure development.

\section{Conclusions}

On the basis of the results of the experimental studies outlined above, it was concluded that:

- The application of the C-S-H nano-admixture has a positive effect on the compressive strength of the cement composites in early periods. In the first hours of curing, the increase in strength is several times higher. After that, it gradually decreases. After $72 \mathrm{~h}$ the influence of the nano-admixture is already negligible. 
- The application of the nano-admixture does not decrease the compressive strength of the composite after 28 days of its curing.

- The application of the C-S-H nano-admixture significantly accelerates the beginning of setting time of the cement paste without shortening the whole curing process.

- The application of the C-S-H nano-admixture and the FA has a positive effect on the cement matrix shrinkage. Samples marked as the FA-20 CSH-0 were characterized by the lowest shrinkage of all tested samples.

- The studies confirm that it is possible to eliminate the negative influence of the FA in the early stages of curing.

- The presented results indicate the possibility of using composites modified with a combined addition of the siliceous fly ashes and the C-S-H nano-admixture as concretes used for printing buildings in the 3D technology.

- It is planned to expand and continue the research undertaken in the field of microstructure analysis of the composites in question, using an electron scanning microscope, and to determine their hydration heat.

\section{References}

1. T.Z. Błaszczyński, M.R. Król, Geopolymers in Construction, Civ. Env. Eng. Rep. 16, 1, 25-40 (2015).

2. Z. Giergiczny, Fly ash and slag, Cem. Concr. Res. 124, 105826 (2019).

3. D.M Gil, G.L. Golewski, Effect of silica fume and siliceous fly ash addition on the fracture toughness of plain concrete in mode I, IOP Conf. Ser.: Mater. Sci. Eng. 416, 012065 (2018).

4. D.M. Gil, G.L. Golewski, Potencial of siliceous fly ash and silica fume as a substitute of binder in cementitious concrete, E3S Web Conf. 49, 00030 (2018).

5. G.L. Golewski, A new principles for implementation and operation of foundations for machines: A review of recent advances, Struct. Eng. Mech. 71, 3, 317-327 (2019).

6. G.L. Golewski, A novel specific requirements for materials used in reinforced concrete composites subjected to dynamic loads, Compos. Struct. 223, 110939 (2019).

7. G.L. Golewski, An analysis of fracture toughness in concrete with fly ash addition considering all models of cracking, IOP Conf. Ser.: Mater. Sci. Eng. 416, 012029 (2018).

8. G.L. Golewski, T. Sadowski, A study of mode III fracture toughness in young and mature concrete with fly ash additive, Sol. State Phenom. 254, 120-125 (2016).

9. G.L. Golewski,T. Sadowski, Experimental investigation and numerical modelling fracture processes under mode II in concrete composites containing fly-ash at early age, Sol. State Phenom. 188, 158-163 (2012).

10. G.L. Golewski, Effect of curing time on the fracture toughness of fly ash concrete composites, Compos. Struct. 185, 105-112 (2018).

11. G.L. Golewski, Energy savings associated with the use of fly ash and nanoadditives in the cement composition, Energies 13, 9, 2184 (2020).

12. G.L. Golewski, Estimation of the optimum content of fly ash in concrete composite based on the analysis of fracture toughness tests using various measuring systems, Constr. Build. Mater. 213, 142-155 (2019).

13. G.L. Golewski, Studies of natural radioactivity of concrete with siliceous fly ash addition, Cem. Wapno Beton 2, 106-114 (2015).

14. G. Golewski, T. Sadowski, Fracture toughness at shear (mode II) of concretes made of natural and broken aggregates, Brittle Matrix Compos. 8, 537-546 (2006). 
15. E.E. Ikponmwosa, S.O. Ehikhuenmen, K.K. Irene, Comparative study and empirical modelling of pulverized coconut shell, periwinkle shell and palm kernel shell as a pozzolans in concrete, Acta Polytech. 59, 6, 560-572 (2019).

16. T.T. Le, S.A. Austin, S. Lim, R.A. Buswell, A.G.F. Gibb, T. Thorpe, Mix design and fresh properties for high-performance printing concrete, Mater. Struct. 45, 8, 1221-1232 (2012).

17. H. Lu, X. Song, R. Wang, H. Chen, Design and Control of Movable Cement 3D Printing System, In: Proceedings of the 31st Chinese Control and Decision Conference (2019 CCDC). 3-5 June, 2019, Nanchang, China. 2019 Chinese Control And Decision Conference (CCDC). Nanchang, China, 6/3/2019 - 6/5/2019. Piscataway, NJ: IEEE, 1239-1242. (2019)

18. K. Pacewicz, A. Sobotka, $Ł$. Gołek, Characteristic of materials for the 3D printed building constructions by additive printing, MATEC Web Conf. 222, 3, 1013 (2018).

19. C.P. Suvash, D.T. Yi Wei, P. Biranchi, J.T. Ming, Fresh and hardened properties of 3D printable cementitious materials for building and construction, Arch. Civ. Mech. Eng. 18, 1, 311-319 (2018).

20. Ł. Sadowski, Results Obtained at the Nano-scale, w: Multi-scale approach for layered systems made of cement composites, ed. Sadowski Łukasz, t. 101.: SPRINGER (Advanced Structured Materials), 149-154 (2019).

21. G. de Schutter, K. Lesage, V. Mechtcherine, V.N. Nerella, G. Habert, G I. Agusti-Juan, Vision of 3D printing with concrete Technical, economic and environmental potentials, Cem. Concr. Res. 112, 25-36 (2018).

22. N.T. Seghir, M. Mellas, Ł. Sadowski, A. Zak, Effects of marble powder on the properties of the air-cured blended cement paste, J. Clean. Prod. 183, 858-868 (2018).

23. B. Szostak, G.L. Golewski, Effect of nano admixture of CSH on selected strength parameters of concrete including fly ash, IOP Conf. Ser.: Mater. Sci. Eng. 416, 12105 (2018)

24. N. Toniolo, V. Bednarzig, J.A. Roether, H. Rost, A.R. Boccaccini, Advancing processing technologies for designed geopolymers: 3D printing and mechanical machining, Interceram - Int. Ceram. Rev. 68, 1-2, 18-21 (2019).

25. J. van der Putten, M. Deprez, V. Cnudde, G. de Schutter, K. van Tittelboom, Microstructural characterization of 3D printed cementitious materials, Materials 12, 18 (2019).

26. T. Xie, G. Yang, X. Zhao, J. Xu, C. Fang, A unified model for predicting the compressive strength of recycled aggregate concrete containing supplementary cementitious materials, J. Clean. Prod. 251, 119752 (2020).

27. J. Ye, M. Zubair, S. Wang, Y. Cai, P. Zhang, Power production waste, Wat. Env. Res. 91, 10, 858-868 (2019).

28. P. Zhang, J. Wan, K. Wang, Q. Li, Influence of nano-SiO ${ }_{2}$ on properties of fresh and hardened high performance concrete: A state of the art review, Constr. Build. Mater. 148, 648-658 (2017).

29. F. Zou, C. Hu, F. Wang, Y. Ruan, S. Hu, Enhancement of early-age strength of the high content fly ash blended cement paste by sodium sulfate and C-S-H seeds towards a greener binder, J. Clean. Prod. 244, 118566 (2020).

30. PN-EN 1015-11: Methods of test for mortar for masonry. Determination of flexural and compressive strength of hardened mortar.

31. PN-EN 12390-2: Testing hardened concrete. Making and curing specimens for strength tests.

32. PN-EN 196-3: Methods of testing cement. Determination of setting times and soundness. 